\title{
A “giant” prolactinoma
}
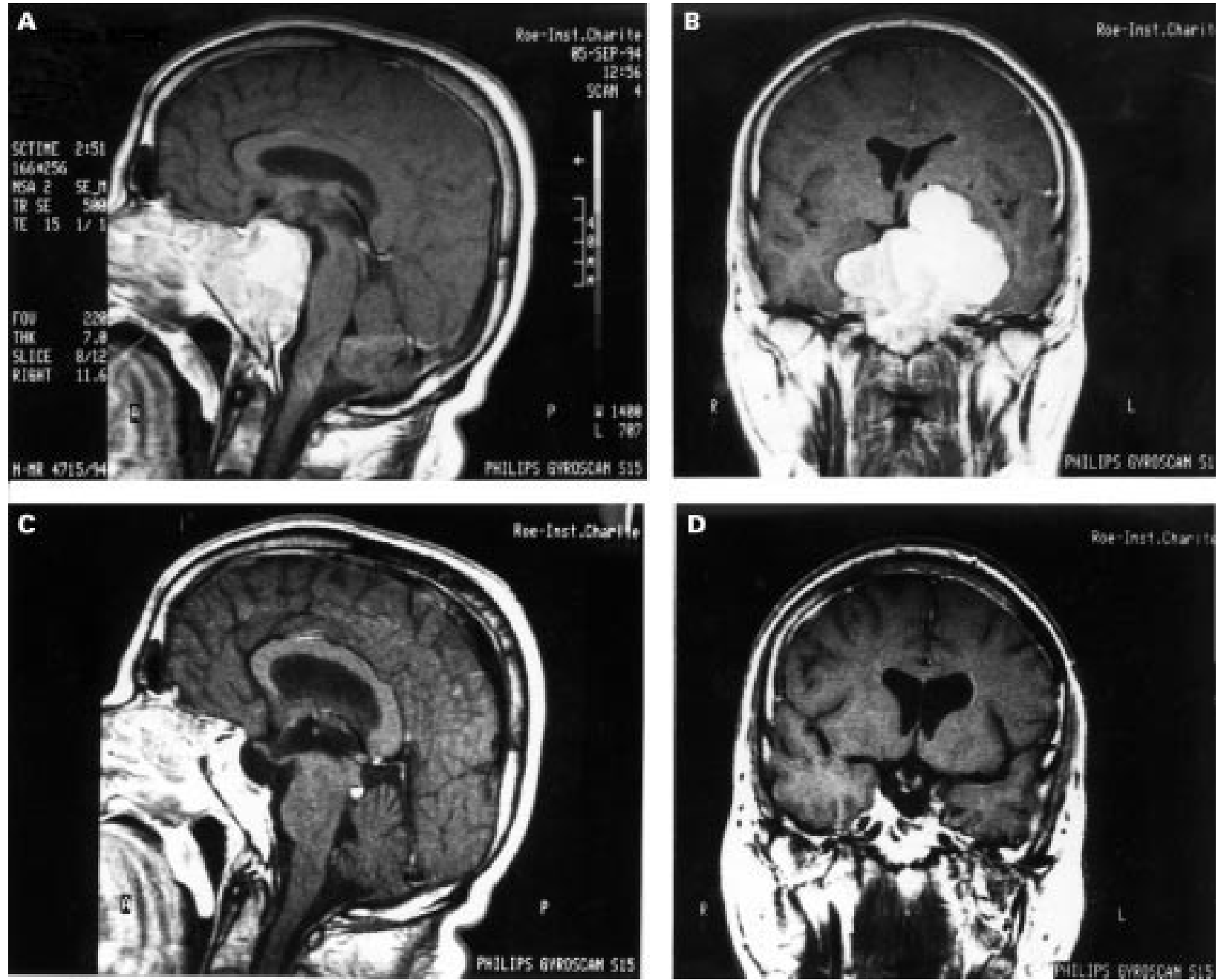

Sagittal and frontal T1 weighted MRI before $(A, B)$ and after $(C, D)$ treatment with bromocriptine

A 43 year old man with a history of epilepsy was admitted after a grand mal seizure. Physical examination showed bilateral loss of visual acuity, a bilateral lateral rectus palsy, and bilateral optic disc pallor. Secondary sexual characteristics were normal. Brain MRI disclosed an enhancing intrasellar and perisellar tumour $(8 \times 8 \times 8 \mathrm{~cm})$ with displacement and compression of the optic chiasm as well as the mesencephalon and diencephalon (figure, A and B). A raised serum prolactin concentration of $24500 \mathrm{ng} / \mathrm{ml}$ (normal $<15 \mathrm{ng} / \mathrm{ml}$ ), the tumour location, and size were consistent with a "giant" prolactinoma. After four weeks of treatment with bromocriptine $(15 \mathrm{mg} /$ day $)$ the bilateral lateral rectus palsies had remitted completely and vision had slightly improved. At that time the serum prolactin concentration had fallen to $1160 \mathrm{ng} / \mathrm{ml}$. A further brain MRI showed a dramatic reduction of tumour size with residual tumour only in the sphenoid and ethmoidal bone (figure, C and D).

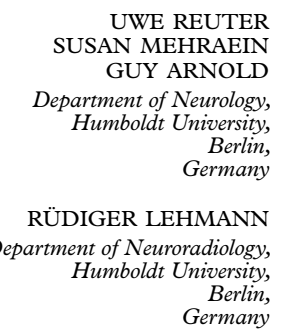

